\title{
Stress Analysis of Automotive Chassis with Various Thicknesses
}

\author{
Hemant B.Patil ${ }^{1}$, Sharad D.Kachave ${ }^{2}$, Eknath R.Deore ${ }^{3}$ \\ ${ }^{1}$ (P.G.Student Mechanical, S.SV.P.S.B.S.D.C.O.Engg, Dhule North Maharashtra University, India) \\ ${ }^{2}$ (Mechanical, S.SV.P.S.B.S.D.C.O.Engg, Dhule North Maharashtra University, India) \\ ${ }^{3}$ (Head of Mechanical, S.SV.P.S.B.S.D.C.O.Engg, Dhule North Maharashtra University, India)
}

\begin{abstract}
This paper presents, stress analysis of a ladder type low loader truck chassis structure consisting of C-beams design for application of 7.5 tonne was performed by using FEM. The commercial finite element package CATIA version 5 was used for the solution of the problem. To reduce the expenses of the chassis of the trucks, the chassis structure design should be changed or the thickness should be decreased. Also determination of the stresses of a truck chassis before manufacturing is important due to the design improvement. In order to achieve a reduction in the magnitude of stress at critical point of the chassis frame, side member thickness, cross member thickness and position of cross member from rear end were varied. Numerical results showed that if the thickness change is not possible, changing the position of cross member may be a good alternative. Computed results are then compared to analytical calculation, where it is found that the maximum deflection agrees well with theoretical approximation but varies on the magnitude aspect.
\end{abstract}

Keywords - Stress analysis, fatigue life prediction and finite element method etc.

\section{INTRODUCTION}

The chassis of trucks is the backbone of vehicles and integrates the main component systems such as the axles, suspension, power train, cab and trailer, and is usually subjected to the weight of cabin, its content, and inertia forces arising due to roughness of road surfaces etc. (i.e. static, dynamic and cyclic loading). The stress analysis is important in fatigue study and life prediction of components to determine the highest stress point commonly known as critical point which initiates to probable failure, this critical point is one of the factors that may cause the fatigue failure. The magnitude of the stress can be used to predict the life span of the chassis. The location of critical stress point is thus important so that the mounting of the components like engine, suspension, transmission and more can be determined and optimized, Finite Element Method (FEM) is one of the method to locate the critical point [1,2]. Safety factor is used to provide a design margin over the theoretical design capacity. This allows consolidation of uncertainties in the design process [3].Jadav Chetan S. et al reviews various factors affecting the fatigue life of an structure like cyclic stress state, geometry, surface quality, material type, residual stresses, size and distribution of internal defects, direction of loading \& grain size [4].

In this study, chassis structures are comparing by the thicknesses of the profiles. For determining the strength of the frame, structural analyses were performed for these frames of thicknesses of 4, 5, $6 \mathrm{~mm}$ and also changing the position of cross member and change the thickness of cross member near high stress zone. The truck chassis was modeled and the finite element analyses were solved in CATIA V5R10.

During this five different cases consider to study the effect of thickness on chassis stresses

- Case 1 Thickness of Side member is $4 \mathrm{~mm}$.

- Case 2 Thickness of Side member is $5 \mathrm{~mm}$.

- Case 3 Thickness of Side member is $6 \mathrm{~mm}$.

- Case 4 Change position of $4^{\text {th }}$ Cross member at 2520 from rear end.

- Case 5 Thickness of $5^{\text {th }}$ Cross member is $5 \mathrm{~mm}$.

\section{LITERATURE REVIEW}

Roslan Abd Rahman et al [1] does stress analysis of heavy duty truck chassis by utilizing a commercial finite element package ABAQUS. To determine critical point so that by design modifications the stresses can be reduces to improve the fatigue life of components. During this he uses ASTM low alloy steel a $710 \mathrm{C}$ (Class 3) with $552 \mathrm{MPa}$ of yield strength and $620 \mathrm{MPa}$ of tensile strength for chassis founds the maximum stress 386.9 $\mathrm{MPa}$ at critical point occurred at opening of chassis This critical point is located at element 86104 and node 16045 , which is in contacted with the bolt from this he concludes that this critical point is an initial to probable failure.

Cicek Karaoglu et al [2] does stress analysis of heavy duty truck chassis with riveted joints by utilizing a commercial finite element package ANSYS version 5.3.during this study, he examine the effect of the side member thickness and connection plate thickness with length change, the side member thickness is varied from 8 to $12 \mathrm{~mm}$, and the thickness of the connection plate is also varied from 8 to $12 \mathrm{~mm}$ by local plate, the 
connection plate thickness is varied from 7 to $10 \mathrm{~mm}$, and the length of the connection plate $(\mathrm{L})$ is varied from 390 to $430 \mathrm{~mm}$. from this he concluded that if the change of the side member thickness using local plates is not possible, due to increase weight of chassis then choosing an optimum connection plate length (L) seems to be best practical solutions for decreasing the stress values.

Mohd Azizi Muhammad Nor et al [3] performs the stress analysis of an actual low loader structure consisting of I-beams design application of 35 tonne trailer. He uses modeling software CATIA V5R18. The results of analysis revealed that the location maximum deflection and maximum stress agrees well with theoretical maximum location of simple beam under uniform loading distribution. This study found out that there is discrepancy between the theoretical (2-D) and numerical (3-D FEA) results. It is observed that the maximum deflection is pointed in situated in between $\mathrm{BC} 1$ and $\mathrm{BC} 2$ with magnitude of $7.79 \mathrm{~mm}$. The results of the numerical analysis revealed that the location maximum deflection and maximum stress agrees well with theoretical maximum location of simple beam loaded by uniform force.

Jadav Chetan $\mathrm{S}$ et al [4] review the investigations that have been made on the different fatigue analysis techniques of automobile frames.

N.K.Ingole et al [5] does the modifications in existing model of tractor trailer chassis by 1) Variation in Cross sectional areas of cross members, 2) Variation in cross sectional areas of cross and longitudinal members, 3) Variation in cross sectional areas of cross and longitudinal members and 4) Changing the position of cross members of main frames of chassis, Considering variable cross sectional areas of cross and longitudinal members. It has been found that, maximum stress present in existing chassis is $75 \mathrm{MPa}$ and weight of chassis is $751.82 \mathrm{~kg}$. Case 4 leads to maximum weight reduction of approx $112 \mathrm{~kg}$ as compared to case 1,2 and 3 . So modifications as per case 4 are also recommended, case 3 the weight reduction is $88 \mathrm{~kg}$ with maximum stress level in range of $25 \mathrm{MPa}$ to $66 \mathrm{MPa}$.

\section{BASIC CALCUlation For ChaSsis Frame}

For Case 1

Model No. $=10.75$ (Eicher)

Side bar of the chassis are made from "C" Channels with $200 \mathrm{~mm}$ x $55 \mathrm{~mm}$ x $5 \mathrm{~mm}$

Front Overhang (a) $=1005 \mathrm{~mm}$.

Rear Overhang $(\mathrm{c})=1305 \mathrm{~mm}$.

Wheel Base $(b)=3515 \mathrm{~mm}$. Material of the chassis is Steel

Table 1Material properties of the Truck Chassis Steel

\begin{tabular}{|l|l|}
\hline Young's Modulus & $200 \mathrm{GPa}$. \\
\hline Poisson's Ratio & 0.266. \\
\hline Density & $7860 \mathrm{Kg} / \mathrm{m}^{3}$. \\
\hline Yield Strength & $250 \mathrm{MPa}$. \\
\hline Symmetry & Linear Isotropic. \\
\hline
\end{tabular}

Capacity of Truck $=7.5$ ton $=7500 \mathrm{~kg}=73575 \mathrm{~N}$.

Capacity of Truck with $1.25 \%=9375 \mathrm{~N}=91968.75 \mathrm{~N}$.

Weight of the body and engine $=2 \mathrm{ton}=2000 \mathrm{~kg}=19620 \mathrm{~N}$

Total load acting on chassis = Capacity of the Chassis + Weight of body and engine

$=91968.75+19620$

$=111588.75 \mathrm{~N}$

Chassis has two beams. So load acting on each beam is half of the Total load acting on the chassis. Load acting on the single frame $=111588.75 / 2=55794.375 \mathrm{~N} /$ Beam.

Uniformly Distributed Load is $55794.375 / 5825=9.578 \mathrm{~N} / \mathrm{mm}$. 


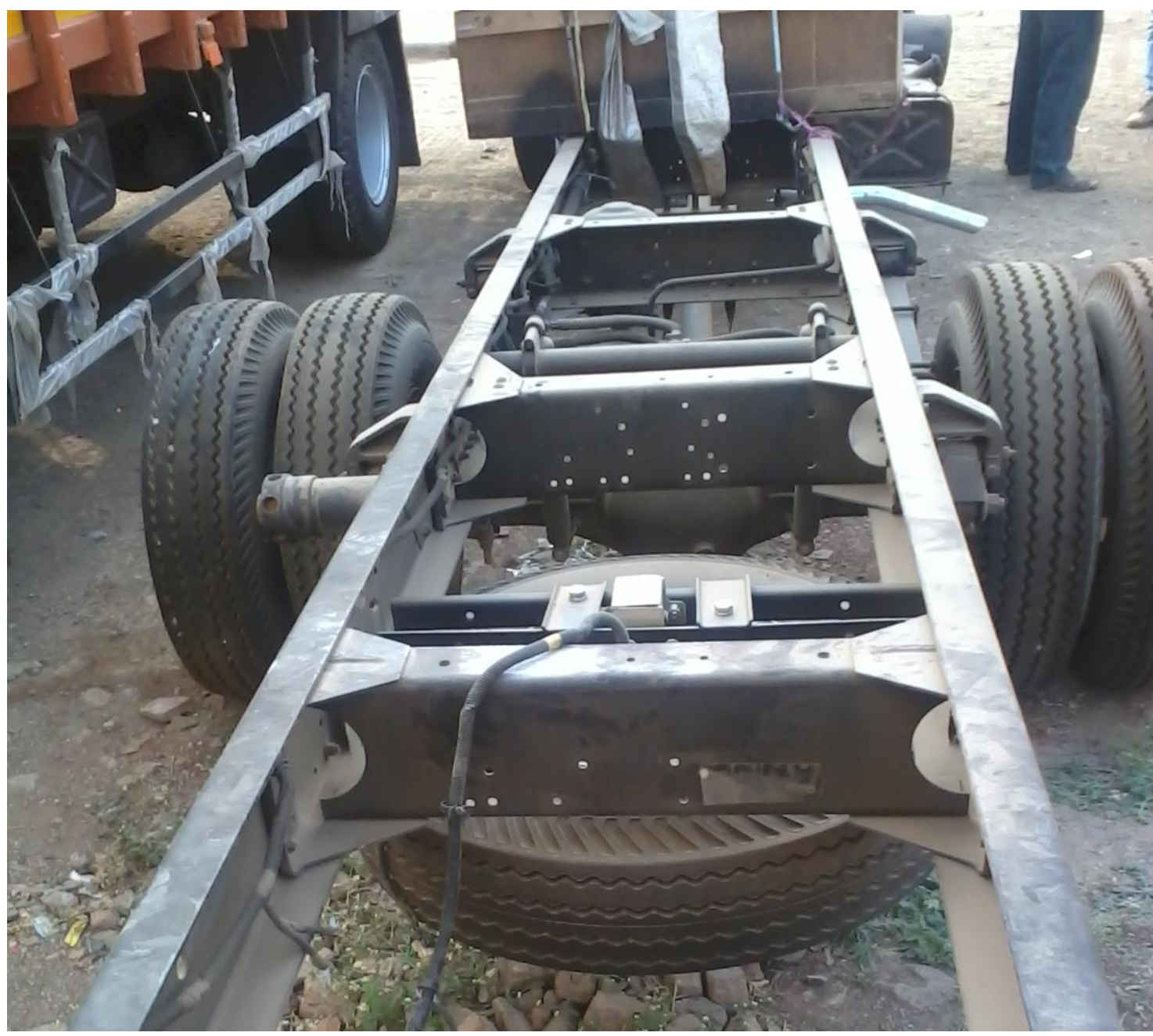

Figure 1Typical Chassis

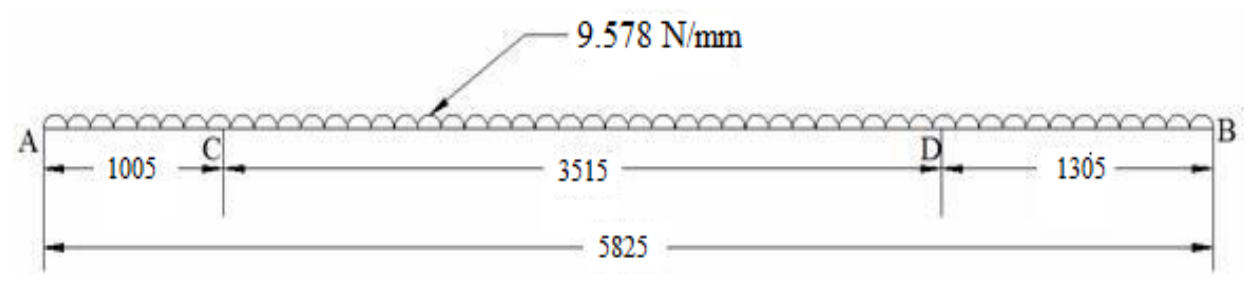

Figure 2Chassis as a simply supported beam with overhang.

Stress produced on the beam is as under

$\sigma=\frac{\mathrm{Mmax}}{\mathrm{Z}}$

$=123.83 \mathrm{MPa}$.

Deflection of chassis

$\mathrm{Y}=\frac{\mathrm{wx}(\mathrm{b}-\mathrm{x})}{24 \mathrm{EI}}\left[\mathrm{x}(\mathrm{b}-\mathrm{x})+\mathrm{b}^{2}-2\left(\mathrm{c}^{2}+\mathrm{a}^{2}\right)-\frac{2}{\mathrm{~b}}\left\{\mathrm{xc}^{2}+\mathrm{a}^{2}(\mathrm{~b}-\mathrm{x})\right\}\right]$

$=1.08456 \mathrm{~mm}$. 
IV.

FE ANALYSIS OF CHASSIS

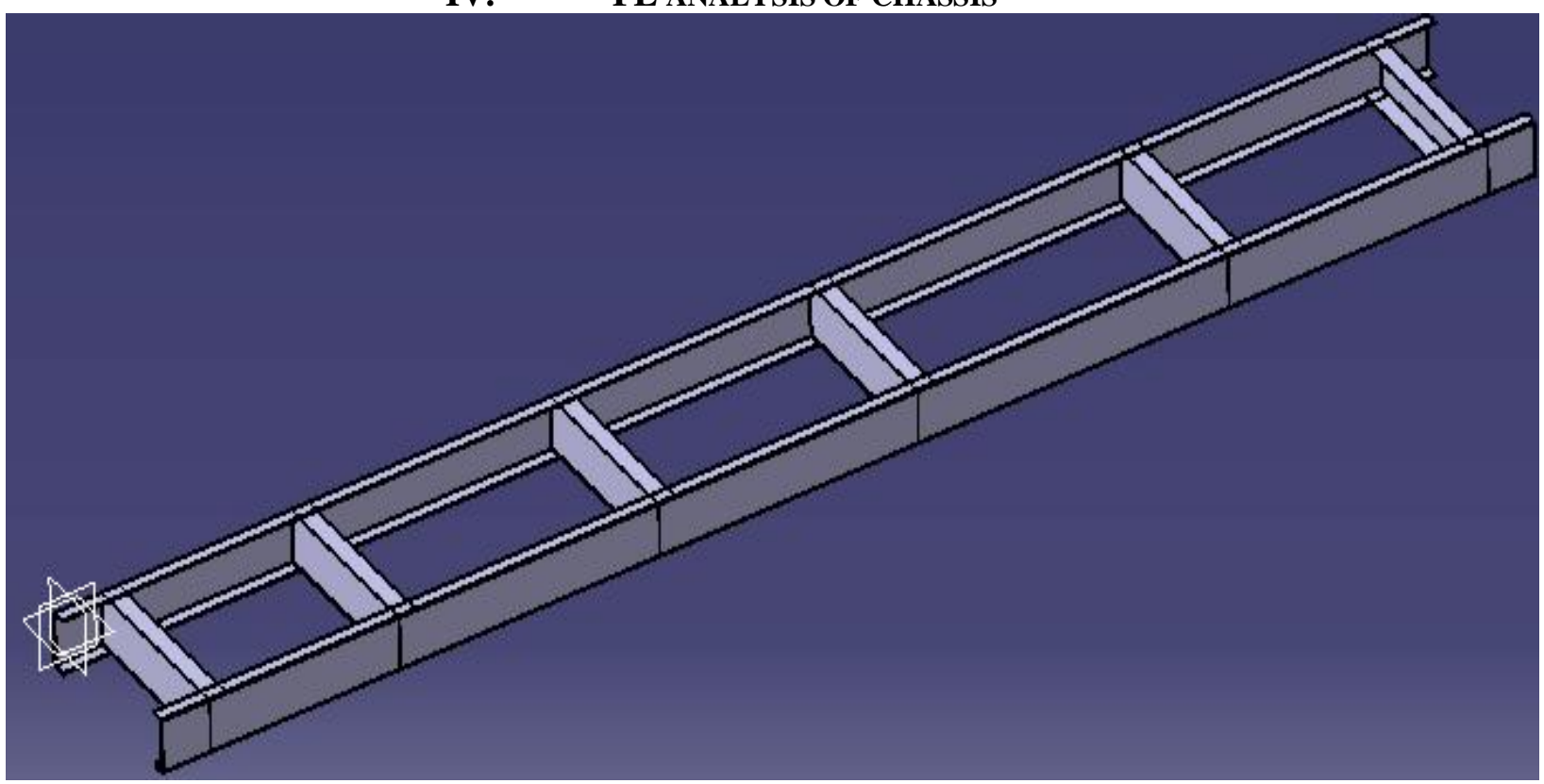

Figure 3Model of Chassis Case 1.

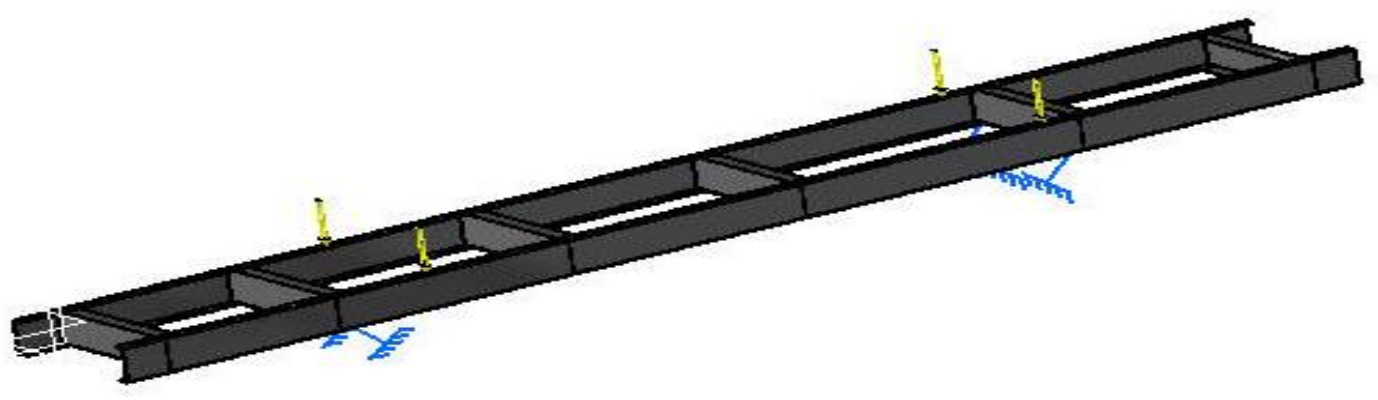

Figure 4Boundary Conditions Case 1.

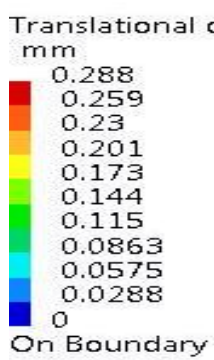

displacement vector. 1 


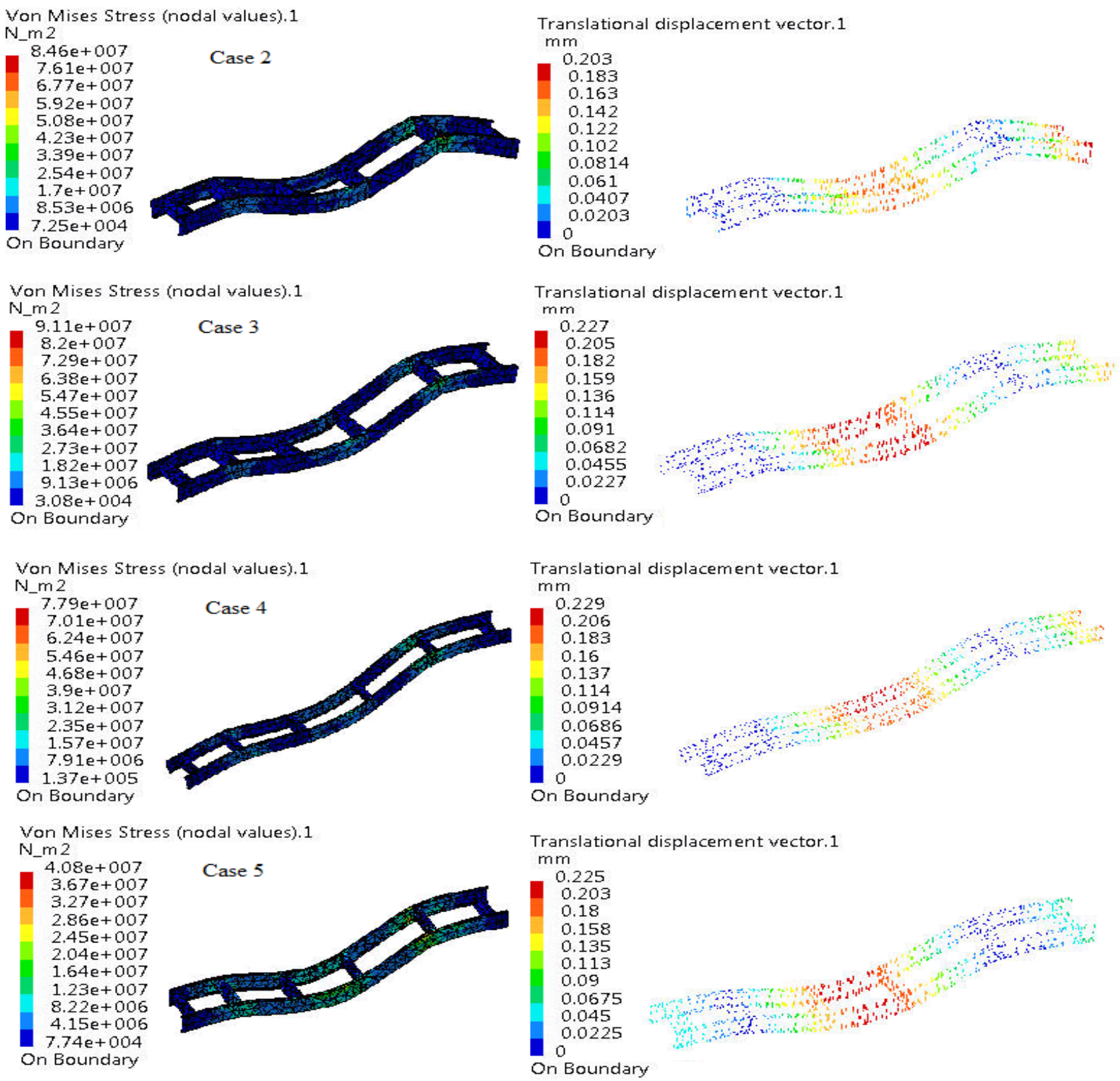

Figure 7 Von Mises Stresses and Displacements of Cases 2, 3, 4 and 5.

V. RESULT AND DisCUSSION

Table 2 Comparison of results

\begin{tabular}{|c|c|c|c|c|c|}
\hline Sr No. & \multicolumn{2}{|c|}{ Analytical Method } & \multicolumn{2}{c|}{ FE Analysis } & \\
\hline & $\begin{array}{c}\text { Displacement } \\
(\mathbf{m m})\end{array}$ & $\begin{array}{c}\text { Stresses } \\
\left(\mathbf{N} / \mathbf{m m}^{\mathbf{2}}\right)\end{array}$ & $\begin{array}{c}\text { Displacement } \\
(\mathbf{m m})\end{array}$ & $\begin{array}{c}\text { Stresses } \\
\left(\mathbf{N} / \mathbf{m m}^{2}\right)\end{array}$ & $\begin{array}{c}\text { Weight } \\
(\mathbf{K g})\end{array}$ \\
\hline Case 1 & 1.0845 & 123.83 & 0.288 & 71.2 & 141.48 \\
\hline Case 2 & 1.0271 & 100.83 & 0.203 & 84.6 & 165.06 \\
\hline Case 3 & 0.9780 & 085.57 & 0.227 & 91.1 & 188.64 \\
\hline Case 4 & 1.0271 & 100.83 & 0.229 & 77.9 & 165.06 \\
\hline Case 5 & 0.9300 & 100.83 & 0.225 & 40.8 & 167.98 \\
\hline
\end{tabular}

\section{Conclusion}

- The analyses are processed in the static and structural conditions. From comparison for $4 \mathrm{~mm}$ thickness the highest stress occurred is $123.83 \mathrm{MPa}$ by FE analysis and the calculated maximum shear stress is 123.83 Mpa. The maximum displacement of numerical simulation result is $0.288 \mathrm{~mm}$. The difference is caused by simplification of model and uncertainties of numerical calculation and improper meshing. 
- Comparing case 5 with case 2 only by increasing thickness of cross member weight is increases by $2.92 \mathrm{Kg}$ stresses are decreased by $43.8 \mathrm{~N} / \mathrm{mm}^{2}$, and displacement is increased by $0.022 \mathrm{~mm}$.

- Comparing case 4 with case 2 only by changing the position of cross member weight is not affecting stresses are deceases by $06.7 \mathrm{~N} / \mathrm{mm}^{2}$, and displacement is increased by $0.026 \mathrm{~mm}$.

- Comparing case 3 with case 2 only by increasing $23.58 \mathrm{Kg}$ stresses are increased by $06.5 \mathrm{~N} / \mathrm{mm}^{2}$, and displacement is increased by $0.024 \mathrm{~mm}$.

Hence it is better to change the thickness of cross member at critical stress point than changing the thickness of side member and position of chassis for reduction in stress values and deflection of chassis.

\section{Acknowledgment}

I express my deep sense of gratitude and Special thanks to Eicher Co. Ltd. authorized show-room \& service center Siddhi Motors Pvt. Ltd., Dhule, for giving me training and required data.

\section{REFERENCES}

[1] Roslan Abd Rahman, Mohd Nasir Tamin, Ojo Kurdi "Stress analysis of heavy duty truck chassis as a preliminary data for its fatigue life prediction using FEM" Jurnal Mekanikal December 2008, No. 26, 76 - 85.

[2] Cicek Karaoglu, N. Sefa Kuralay "Stress analysis of a truck chassis with riveted joints" Elsevier Science B.V Finite Elements in Analysis and Design 38 (2002) 1115-1130.

[3] Mohd Azizi Muhammad Nora,, Helmi Rashida, Wan Mohd Faizul Wan Mahyuddin "Stress Analysis of a Low Loader Chassis" Elsevier Ltd. Sci Verse Science Direct Procedia Engineering 41 ( 2012 ) 995 - 1001

[4] Jadav Chetan S., Panchal Khushbu C., Patel Fajalhusen "A Review of the Fatigue Analysis of an Automobile Frames" International Journal of Advanced Computer Research, Volume-2 Number-4 Issue-6 December-2012, (ISSN (print): 2249-7277 ISSN (online): 2277-7970).

[5] N.K.Ingole, D.V. Bhope "Stress analysis of tractor trailer chassis for self weight reduction" International Journal of Engineering Science and Technology (IJEST), ISSN: 0975-5462 Vol. 3 No. 9 September 2011

[6] I. Kutay Yilmazcoban, Yaşar Kahraman "Truck chassis structural thickness optimization with the help of finite element technique" TOJSAT the Online Journal of Science and Technology - Volume 1, Issue 3, July 2011.

[7] Patel Vijay kumar V, Prof. R. I. Patel "Structural Analysis of Automotive Chassis Frame and Design Modification for Weight Reduction” International Journal of Engineering Research \& Technology (IJERT), ISSN: 2278-0181, Vol. 1 Issue 3, May - 2012.

[8] Beam formula with shear and moment diagram, American forest and paper association, Inc, American Wood Council, 1111 19th St., NW. Suite 800, Washington. DC 20036, 202 - 463 - 4713. 